\title{
Kawasaki Disease: an Update
}

\author{
Eileen Rife ${ }^{1}$. Abraham Gedalia ${ }^{2}$
}

Published online: 13 September 2020

(C) Springer Science+Business Media, LLC, part of Springer Nature 2020

\begin{abstract}
Purpose of Review Provide the most recent updates on the epidemiology, pathogenesis, and treatment advances in Kawasaki disease. Recent Findings Treatment advances in complex, IVIG-refractory cases of Kawasaki disease. Multisystem inflammatory syndrome, a newly reported inflammatory condition with Kawasaki-like features and an association with the 2019 Coronavirus (COVID-19).

Summary Kawasaki disease (KD) is a rare systemic inflammatory disease that predominately affects children less than 5 years of age. Pathogenesis of KD remains unknown; the leading theory is that an unknown stimulus triggers an immune-mediated inflammatory cascade in a genetically susceptible child. Classic KD is a clinical diagnosis based on set criteria and excluding other similar clinical entities. Patients who do not fulfill complete diagnostic criteria for KD are often referred to as atypical (or incomplete) KD. The most feared complication of KD is coronary artery abnormality development, and patients with atypical KD are also at risk. Administration of intravenous immunoglobulin (IVIG) and aspirin has greatly reduced the incidence of coronary lesions in affected children. Several other immune-modulating therapies have recently been utilized in complex or refractory cases.
\end{abstract}

Keywords Kawasaki disease $\cdot$ Kawasaki review $\cdot$ Kawasaki treatment $\cdot$ Kawasaki workup $\cdot$ Kawasaki differential $\cdot$ Kawasaki diagnosis $\cdot$ Multi system inflammatory syndrome $\cdot$ Kawasaki-like disease

\section{Introduction}

Kawasaki disease (KD) was first described in a 1967 report by Japanese pediatrician Tomisaku Kawasaki. The cardiac sequelae were later documented in 1970, following investigation of 10 autopsy cases of sudden cardiac death following diagnosis of KD. The first reported cases outside Japan were in Hawaii in the early 1970s; KD cases have since been reported in more than 60 countries worldwide.

\section{Epidemiology}

The epidemiology of KD varies greatly by geographic location and seasonality. The highest incidence rates (per 100,000)

\author{
This article is part of the Topical Collection on Vasculitis \\ Eileen Rife \\ erife@1suhsc.edu \\ $\triangle$ Abraham Gedalia \\ AGedal@1suhsc.edu \\ Louisiana State University, New Orleans, LA, USA \\ 2 Division of Pediatric Rheumatology, Children's Hospital and LSU \\ Health Sciences Center, 2000 Henry Clay Avenue, New \\ Orleans, LA 70118, USA
}

are in children of Japanese ancestry. Recently published data from the Japanese KD nationwide survey reported an increased rate over time from 218.6 per 100,000 in 2008 to 243.1 and 330.2 in 2011 and 2015 respectively $[1 \bullet, 2]$. In the United States, the incidence appears to have remained relatively stable. In 2012, the KD-associated hospitalization rate for children $<5$ years of age was 18.1 per 100,000 . In 2003, the rate was 19.7 per 100,000 children, [3] which amounts to roughly 4000 to 5500 new cases in the United States each year. The highest rates are seen among children $<5$ years of age, with a male predominance ( 21.0 per 100,000 versus 15 per 100,000 in females). There is considerable ethnic variation, the highest rates seen among Asian/Pacific Islanders at 29.8 per 100,000 children $<5$ years, and the lowest recorded rate among white children 13.7 per 100,000 [3, 4]. It should be pointed out that analysis of Black and Hispanic race/ethnic groups could not be carried out in the Holman study as there were too few reported cases [4].

\section{Pathogenesis}

\section{Genetics}

Although poorly understood, the predilection for children of East Asian and Pacific Islander descent, even with transmigration, 
supports the likely role genetics plays in pathogenesis of $\mathrm{KD}[5$, 6]. Several additional findings support a genetic component to KD susceptibility, including: concordance risk in identical twins at $\sim 13 \%$, increased incidence of $\mathrm{KD}$ in children whose parents have a history of KD, and higher occurrence of $\mathrm{KD}$ in siblings of affected patients [7-12].

KD does not appear to follow Mendelian pattern of inheritance. However, familial aggregation is well recognized, as are prediction models for severity based on genetic differences. Several single-nucleotide polymorphisms (SNPs) in different genes and gene regions have been implicated in family linkage and genome association studies: caspase 3 (CASP3), inositol 1,4,5-trisphosphate kinase-C (ITPKC), CD40, FCGR2a, and B- cell lymphoid kinase (BLK) [13-15]. Interestingly, many of the SNPs associated with KD have been identified in other inflammatory diseases such as rheumatoid arthritis, ulcerative colitis, systemic lupus erythematosus, and systemic sclerosis. These findings may indicate a common pathway in the inflammatory immune response [16].

\section{Vaccine Exposure Theory}

Several studies have evaluated the role vaccination may play in triggering $\mathrm{KD}$ via robust stimulation of the innate and adaptive arms of the immune system. However, there is currently no evidence to suggest that vaccine administration is associated with development of $\mathrm{KD}$ [17-20].

\section{Infectious Theory/Seasonality}

The leading theory for the pathogenesis of $\mathrm{KD}$ is that an unknown infectious agent leads to activation of the immune system in a genetically susceptible child. Several epidemiologic phenomena support this theory. The first is the apparent seasonality of $\mathrm{KD}$. There is a consistent peak in the number of cases reported in the month of January, with another gradual increase in spring to summer (March-June) $[1 \bullet, 21]$. We often see this kind of consistent seasonal fluctuation in relation to infectious agents, especially viral infections. Several temporal clusters of epidemics have been reported in Japan, Canada, the United States, and Finland further supporting an infectious trigger [22].

The next supporting feature is related to tropospheric wind patterns whose presence in different locations may coincide with the incidence of KD. Studies suggest that winds arising from certain regions may carry either environmental toxins or an infectious agent to another region, thus triggering development of KD [23-25]. Another supporting feature is the significant overlap of clinical features between $\mathrm{KD}$ and other infectious agents, most notably scarlet fever, the newly described multisystem inflammatory syndrome (described in detail below), and adenovirus. In one study, it was found that $10 \%$ of patients diagnosed with $\mathrm{KD}$ also had positive low titer adenovirus infection [26].

There is a mono-modal age distribution in the occurrence of KD with peak incidence in late infancy (9-11 months), and then a gradual decrease in incidence with advancing age [1•]. This suggests the possible existence of protective transplacental antibodies to infection, which wanes after the first few months of life [27]. Finally, there are case reports/series showing higher occurrence of KD cases among siblings. The risk of $\mathrm{KD}$ in a child is increased roughly 10 times if a sibling has also been affected. This temporally occurs either on the same day or within 10 days of the initial presentation [7].

\section{Immune Factors/Dysregulation}

To date, no infectious causes have been identified as potential underlying etiologies, despite many investigations into bacterial toxins, super-antigens, fungal organisms, and viral pathogens. The theory remains, however, that an unknown stimulus triggers an inflammatory cascade with activation of both the innate and adaptive arms of the immune system. The innate immune system may be activated via detection of either pathogen-associated molecular patterns (PAMPs), or damage-associated molecular patterns (DAMPs). The NLRP3 inflammasome recognizes these abnormal molecular patterns in the body and activates a signaling cascade, which ultimately results in downstream release of several proinflammatory cytokines. Some of the most well studied of these cytokines in KD include IL-1, IL-18, IL-6, TNF-a, IFN-gamma, and IL-8. Several studies have either implicated this pathway of innate activation, or have successfully induced coronary arteritis (resembling $\mathrm{KD}$ ) in murine models via these innate mechanisms [28-30]. Interleukin-1 has direct inflammatory effects on coronary artery endothelial cells.

In addition to the innate immune response in activating inflammatory mechanisms in $\mathrm{KD}$, there is also significant activation of the adaptive (antigen-specific) immune response. There appears to be increased numbers of circulating proinflammatory and regulatory $\mathrm{T}$ cells in the acute phase of KD [31]. Studies have noted an increased number of IgAproducing plasma cells in tissues and coronary artery vascular walls in affected patients with $\mathrm{KD}[32,33]$. Several autoantibodies directed against myocardial, endothelial, and extracellular matrix proteins have also been described in the literature, although their clinical significance is poorly understood [34]. Following administration of IVIG, we see an expansion of regulatory $\mathrm{T}$ cell populations and normalization of $\mathrm{B}$ cellactivating factor. This is associated with subsequent clinical improvement during the acute phase of $\operatorname{KD}[35,36]$. All of the aforementioned findings support the significant role adaptive immune system plays in KD. B and T cell memory cell development is likely involved as well given the low recurrence rate of KD and typically self-limited course of the disease. 


\section{Diagnosis}

There is no diagnostic test for $\mathrm{KD}$, instead, the diagnosis of classic (or complete) Kawasaki disease is made utilizing clinical criteria (Table 1) and excluding other similar clinical entities. Individual clinical manifestations may not all present simultaneously. Careful review may reveal that one or more clinical features were present and resolved prior to presentation. Several other clinical manifestations may also be present which are not included in the diagnostic criteria (Table 2).

Patients who do not fulfill the complete diagnostic criteria for $\mathrm{KD}$ are referred to as incomplete or atypical KD. These patients may still be at risk for coronary artery abnormalities [37]. Therefore, any child with prolonged unexplained fever with any of the principal clinical features should be further evaluated for KD with consideration of echocardiography. The American Heart Associated (AHA) created an algorithm to aid in evaluation of suspected KD patients who do not meet the diagnostic criteria [38 ${ }^{\bullet}$.

Kawasaki disease tends to be triphasic with an acute, subacute, and convalescent phase. The acute phase is characterized by high-spiking fevers (typically $>39.0^{\circ} \mathrm{C}$ ), with the other principal features listed in table 1 . The acute febrile phase lasts anywhere from 7 to 14 days. The subacute phase is often an asymptomatic period after the febrile episode subsides and extends approximately 4 weeks. During this phase, patients may still have desquamation of the digits, arthralgias, and abnormal lab findings. This is the period of time notable for the greatest risk (highest incidence) of developing cardiac sequelae, namely coronary artery aneurysms (CAA). The third, convalescent phase is typically an asymptomatic period, roughly 4-8 weeks after onset of initial illness. There is still a risk (but significantly decreased) of aneurysm development despite absence of clinical symptoms during this period.

The rate of KD recurrence is less than $3 \%$ of patients in Japan, [39] and roughly $1.7 \%$ of patients in the United States
(3.5\% in US KD patients of Asian and Pacific Islander descent) [40]. There is reportedly a higher risk of coronary artery sequelae with recurrent episodes [22].

\section{Laboratory Analysis and Workup}

Kawasaki disease is a clinical diagnosis based on set diagnostic criteria. Laboratory findings, although nonspecific, are useful in supporting a diagnosis of $\mathrm{KD}$, particularly when the clinical manifestations are non-classic. Table 3 outlines several common laboratory findings seen in $\mathrm{KD}$ during different phases of disease [41, 42].

Most children with KD will typically present in the acute phase with leukocytosis (elevated immature and mature granulocytes). Anemia is another common finding and tends to be normocytic and normochromic. Thrombocytosis is common after the first week of symptoms; counts peak in the third week, and may reach as high as $1,000,000$ per $\mathrm{mm}^{3}$ (average $\sim 700,000$ per $\mathrm{mm}^{3}$ ) before normalizing in the subacute to convalescent phase. Acute phase reactants are elevated to varying degrees in nearly every patient with $\mathrm{KD}$. Serum transaminases or gamma-glutamyl transpeptidase elevations occur in $40-60 \%$ of patients $[2,43]$. Urinalysis may show a sterile pyuria in up to $80 \%$ of children [44].

Some studies suggest use of N-terminal pro-brain natriuretic peptide as an adjunctive diagnostic marker of acute phase $\mathrm{KD}$. Its suggested use is in the pediatric emergency room in patients with unexplained prolonged fever with suspected KD. However, it is a nonspecific test with no clear cut-point values for a positive result [45-47]. A recent study investigated the use of platelet-activating factor (PAF) and its acetyl-hydrolase (PAF-AH) in predicting KD. In this particular report, the authors found a statistically significant elevation in PAF and PAF-AH levels in the acute phase in children with $\mathrm{KD}$ as compared to controls [48•].
Table 1 Diagnostic criteria for Kawasaki disease

\begin{tabular}{ll}
\hline Criteria & Clinical features \\
\hline 1. Mucosal changes & $\begin{array}{l}\text { Erythema and cracking of lips } \\
\text { "Strawberry tongue" erythema and prominent fungiform papillae } \\
\text { and/or erythema of the oral and pharyngeal mucosa. }\end{array}$ \\
$\begin{array}{l}\text { Bilateral bulbar nonexudative conjunctival injection, often limbic sparing } \\
\text { 2. Conjunctivitis }\end{array}$ & $\begin{array}{l}\text { Maculopapular diffuse erythroderma or erythema multiforme-like. } \\
\text { 3. Polymorphous rash }\end{array}$ \\
4. Extremity changes & $\begin{array}{l}\text { Acute phase: erythema and edema of the hands and feet } \\
\text { Subate phase: periungual desquamation }\end{array}$ \\
& Acute, non-suppurative, cervical lymphadenopathy \\
& $(\geq 1.5$ cm diameter), typically unilateral \\
\hline
\end{tabular}

To be diagnosed with classic KD, the patient must have $\geq 5$ days of fever as well as $\geq 4$ of the 5 principal clinical features. In rare cases, experienced clinicians may be able to establish the diagnosis with less than the required duration of fever 
Table 2 Other (less common) clinical manifestations of KD

Cardiovascular:

- Myocarditis, pericarditis

- Valvular regurgitation, aortic root enlargement

- Shock

- Coronary artery abnormalities

- Aneurysms of medium-sized noncoronary arteries

- Peripheral gangrene

Respiratory

- Peri-bronchial and interstitial infiltrates on chest radiography

- Pulmonary nodules

- Pleural effusion

- Empyema

- Very rarely pneumothorax

Musculoskeletal

- Arthralgias and arthritis

Gastrointestinal

- Abdominal pain

- Vomiting, diarrhea

- Hepatitis with jaundice

- Hydrops of the gallbladder

- Pancreatitis

Nervous system

- Behavior changes and irritability

- Aseptic meningitis

- Peripheral facial nerve palsy

- Sensorineural hearing loss

- Cerebral vascular accidents

- Syndrome of inappropriate antidiuretic hormone secretion

Genitourinary

- Urethritis, meatitis

- Hydrocele

- Phimosis

Other

- Desquamating rash in groin

- Retropharyngeal phlegmon

- Anterior uveitis by slit lamp examination

\section{Diagnostics/Imaging}

The most feared sequelae of $\mathrm{KD}$ is development of coronary artery abnormalities, which occurs in $20-25 \%$ of untreated children [49]. Echocardiography remains the standard imaging modality to evaluate for both coronary artery dimension as well as other cardiac abnormalities. It is a non-invasive study without risk of radiation and high sensitivity and specificity for identifying coronary artery lesions (CALs). The Japanese Ministry of Health criteria is widely used to classify coronary artery sizes according to age [50]. In children younger than 5 years, coronary artery lumen diameter is abnormal if exceeding $3 \mathrm{~mm}$. In children 5 years of age and older, a lumen diameter greater than $4 \mathrm{~mm}$ is considered abnormal. In addition to absolute luminal dimensions, both the Japanese ministry of Health and the American Heart Association also utilize $Z$ scores when classifying CALs. $Z$ scores are coronary dimensions that are adjusted for body surface area, as coronary artery dimensions will change with the size of the child. Overall, aneurysms $<5 \mathrm{~mm}$ luminal diameter are considered small, 5-8 mm luminal diameter are considered mediumsized, and aneurysms $>8 \mathrm{~mm}$ in luminal diameter are considered large.
Table 3 Common laboratory findings in $\mathrm{KD}$

\begin{tabular}{ll} 
White blood count (WBC) & $\begin{array}{c}> \\
\text { immature forms) } \\
\text { Anemia (for age) }\end{array}$ \\
Hemoglobin & $>450,000$ per $\mathrm{mm}^{3}$ (peaks in the third week) \\
Platelets & $>40 \mathrm{~mm} / \mathrm{h}$ \\
Sedimentation rate & $>3.0 \mathrm{~g} / \mathrm{dL}$ \\
CRP & $<3.0 \mathrm{~g} / \mathrm{dL}$ \\
Albumin & Elevation above normal range \\
Ferritin & Elevation above normal range \\
Alanine aminotransferase & \\
(ALT) & Elevation above normal range \\
GGT & $>10$ WBCs per high powered field \\
Urine WBCs & Mononuclear pleocytosis without \\
Cerebrospinal fluid & hypoglycorrhachia \\
& and/or elevated protein \\
\hline
\end{tabular}

Echocardiography surveillance is typically performed at diagnosis, 1-2 weeks after diagnosis, and then again 68 weeks later (assuming no complications). There are several factors associated with increased risk of developing CALs including male sex, age $<12$ months or $>8$ years, fever duration $>10$ days, leukocytosis $>15,000$ per $\mathrm{mm}^{3}$, low hemoglobin $(<10 \mathrm{~g} / \mathrm{dL})$, thrombocytopenia, hypoalbuminemia, hyponatremia, and persistent fever or recurrence of fever $>$ $36 \mathrm{~h}$ after IVIG administration [51, 52]. Children at higher risk, and those with previously noted CALs, will be screened more often. Other imaging modalities utilized include magnetic resonance angiography, computed tomographic angiography, and cardiac catheterization if warranted.

\section{Differential}

Several other illnesses share similar clinical features to KD (Table 4) and must be considered prior to diagnosis. Clinical manifestations that do not align with the diagnostic criteria for KD should prompt investigation of other causes. It must also be noted, that children affected by KD may have a concurrent infection with another pathogen, i.e., viral respiratory pathogen as previously described.

Multisystem inflammatory syndrome in children (MIS-C) is a newly reported inflammatory condition with Kawasakilike features and an association with the 2019 Coronavirus (COVID-19). First described April 2020 in the UK, MIS-C cases are now reported in Italy, France, Spain, and the United States. Affected children tend to present with persistent fever, conjunctivitis, mucositis, lymphadenopathy, rash, evidence of multisystem organ involvement, and elevated inflammatory markers. Respiratory symptoms and abdominal pain are also common features $[53 \bullet, 54 \bullet, 55 \bullet, 56 \bullet, 57 \bullet]$. The Centers for Disease Control (CDC) case definition for MIS-C includes 
Table 4 Differential diagnosis of Kawasaki disease

\begin{tabular}{ll}
\hline Viral & Measles \\
& Adenovirus \\
& Enterovirus \\
& Epstein-Barr virus \\
& Scarlet fever \\
& Acute rheumatic fever \\
Bacterial & Rocky mountain spotted fever \\
& Leptospirosis \\
& Cervical lymphadenitis \\
& Staphylococcal scalded skin syndrome \\
Toxin-mediated & Toxic shock syndrome \\
& Drug hypersensitivity reaction \\
Hypersensitivity reactions & Steven-Johnson syndrome \\
& Juvenile idiopathic arthritis \\
Rheumatic disease & Polyarteritis nodosa \\
& Reactive arthritis \\
Toxicity & Acrodynia (mercury poisoning) \\
Other & Multisystem inflammatory syndrome \\
& in children \\
\hline
\end{tabular}

individuals less than 21 years of age presenting with fever (> $38.0^{\circ} \mathrm{C}$ ), laboratory evidence of inflammation, and clinically severe illness requiring hospitalization with multisystem organ involvement. Patients must have evidence of exposure to COVID-19 within 4 weeks prior to onset of symptoms, and practitioners must exclude plausible alternative diagnoses [58•].

MIS-C appears to present as a late manifestation of disease (weeks after the COVID-19 exposure) and may be more related to immune activation during the convalescent period. It remains unknown if COVID-19 triggers KD features, if it is a completely separate entity, a spectrum of disease, related to macrophage activation, or an overlap syndrome. One of the most interesting aspects of this disease is that countries with the highest incidence of KD, i.e., Japan and China, have no reported cases despite excellent surveillance systems. Other notable differences compared to KD: MIS-C typically presents after the age of 5 , and there appears to be a higher incidence in children of Afro-Caribbean descent [54•, 57•]. Little information is currently known about the pathogenesis and optimal treatment regimen for MIS-C. Most practitioners are utilizing standard Kawasaki protocols if clinically similar to $\mathrm{KD}$ in addition to supportive therapy $\left[54^{\bullet}, 55^{\bullet}, 56 \bullet, 57 \bullet\right]$. Several international registries are collecting surveillance data to learn more about this new entity. The hope is that discoveries in MIS-C may provide insight into our understanding of the trigger, genetics, and pathophysiology of KD.

\section{Primary Treatment}

\section{Intravenous Immunoglobulin (IVIG)}

Early identification of KD is paramount as timely administration of treatment has greatly reduced the incidence of coronary artery lesions (CALs). IVIG is most effective when administered within 10 days of onset of fever, and its use decreases the risk of coronary artery aneurysm formation from $20-25 \%$ to $3-5 \%$ in those who are appropriately treated $[59,60]$. Effective initial treatment consists of a single infusion of high-dose IVIG at $2 \mathrm{~g} / \mathrm{kg}$ together with acetylsalicylic acid (ASA) [60-62].

Even with prompt IVIG therapy, up to $20 \%$ of children will develop recurrent or persistent fevers. These children are termed IVIG-resistant [61-63]. There are several risk factors for IVIG-resistant KD including delayed initial IVIG administration, increased ESR, decreased hemoglobin and platelet levels, oral mucosal alterations, cervical lymphadenopathy, extremity swelling, and polymorphous rash [64•]. It is recommended that these children are administered a second dose of IVIG to help prevent sequelae [61]. Additional considerations regarding IVIG therapy: active vaccinations, i.e., measles and varicella vaccinations are contraindicated for 11 months after administration of IVIG and known physiologic ESR elevations after IVIG preclude its use to assess response to therapy.

\section{ASA}

Moderate-dose (30-50 mg/kg/day) or high-dose (80 to $100 \mathrm{mg} / \mathrm{kg} /$ day) ASA is generally utilized until the patient is afebrile in the United States, Japan, and Western Europe. There does not appear to be a significant difference between low-dose (3-5 mg/kg/day) ASA versus high-dose ASA in regard to incidence of CALs, duration of fever, or duration of hospitalization [65•]. There is also no clear evidence that any dose of ASA will decrease development of CALs [66].

Therefore, it may be reasonable to give the moderate-dose ASA to avoid potential toxicities seen in high-dose ASA. Regardless of dose, ASA and IVIG remain the standard initial management. ASA is typically scheduled every $6 \mathrm{~h}$ during the acute phase of illness. Some clinicians will continue high-dose ASA until the 14th day of illness, even after fever defervescence. After the acute phase, children are transitioned to lowdose (3-5 mg/kg) ASA for anti-platelet effect. Patients remain on low-dose ASA into the convalescent phase. The decision to continue or discontinue therapy is usually made around 68 weeks pending any CALs on echocardiogram. Patients who are at high risk of treatment resistance and/or patients with coronary sequelae may benefit from adjunctive treatments (which are discussed below).

\section{Adjuvant Therapy and Treatment Options for Cases Refractory to IVIG and ASA}

\section{Corticosteroids}

Corticosteroids are well-utilized in most vasculitides given their relatively fast onset, strong anti-inflammatory properties, 
and overall improved outcomes. Their use in $\mathrm{KD}$ is more controversial, but emerging data suggests that patients at particularly high risk for development of CALs may benefit from early use of corticosteroids as primary adjunctive therapy with IVIG and ASA. A 2016 meta-analysis of 16 studies by Chen et al. looked at early intervention with corticosteroids plus IVIG versus corticosteroid use in IVIG-resistant cases. They found that the incidence of CALs was lower in patients who received corticosteroids as adjunctive primary therapy compared to the IVIG only group [67]. A 2017 Cochrane review also demonstrated reduced incidence of CALs in KD patients treated with corticosteroids during the acute phase. Additionally, they found that corticosteroid use was associated with decreased duration of fever, length of hospitalization, and time to normalization of CRP [68•].

There is significant heterogeneity in studies assessing corticosteroids use in $\mathrm{KD}$ with regard to dose, duration, and timing of use. Despite this fact, there are several notable consistencies when comparing results. Studies that utilized a single dose of intravenous methylprednisolone $[69,70]$ did not demonstrate the same benefit of reduced incidence of CALs seen in studies which utilized moderate to high dose (i.e., $1-6 \mathrm{mg} / \mathrm{kg} /$ day prednisolone equivalent doses) over an extended course (i.e., greater than 3 days) $[71,72]$. Early use of corticosteroids during the acute phase appears to be more beneficial than in refractory (IVIG-resistant) cases $[67,73]$. Patients at higher risk of poor coronary outcomes have the greatest magnitude of benefit from early adjunctive corticosteroid therapy $[68,69,72,74]$. Overall results demonstrate good tolerability and safety with corticosteroid use and no evidence of increased incidence of adverse outcomes. There is currently no consensus on corticosteroid dosing for treatment of $\mathrm{KD}$. The most recent AHA guidelines note that a longer course of corticosteroids may be considered in high risk patients as primary adjunctive therapy or in IVIG-resistant cases [38•].

\section{Tumor Necrosis Factor (TNF) Inhibition}

TNF and IL-1 beta have both been implicated in the vascular endothelial cell damage and CALs seen in acute KD [75]. Several small studies reported potential beneficial effects of TNF blockade during the acute phase of $\mathrm{KD}$, either as primary therapy or in cases refractory to IVIG. The most well-studied agent is infliximab, whose use may decrease the duration of fever and the length of hospitalization as well as aid in normalization of acute phase reactants. No studies to date, however, have reported decreased CALs with the use of infliximab [76, 77].

A recent trial with etanercept for acute phase $\mathrm{KD}$ showed no significant benefit in cases refractory to IVIG. However, there did appear to be an improvement in coronary artery dilation and disease progression in patients 1 year out from onset. This effect seemed especially true in patients with baseline abnormalities on coronary imaging [78•]. Use of TNF inhibitors is not mainstream for reasons besides lack of effect on CALs, namely association with malignancy and infection risk.

\section{Interleukin 1 Inhibition}

Several small case studies have reported successful use of anakinra, an IL-1 receptor antagonist, in the treatment of refractory KD [79-81]. Prospective trials are underway to further investigate.

\section{Calcineurin Inhibition}

Calcineurin inhibitors like cyclosporine may be beneficial as adjunctive primary treatment or in cases refractory to IVIG [82•, 83, 84]. The 2019 Hamada et al. study was a randomized control trial that showed reduced incidence of CALs in higher risk patients treated with IVIG plus cyclosporine versus standard therapy with IVIG alone. Additionally, the authors found no increased incidence of adverse events between the two groups [82•]. Calcineurin inhibition therapy has promise given the important role the adaptive immune system, specifically $\mathrm{T}$ cells, plays in the pathogenesis of $\mathrm{KD}$. More studies need to be conducted to assess effectiveness and safety.

\section{Other Therapies}

Several other immunosuppressive agents are reported to be effective in patients with refractory KD including: plasma exchange, cyclophosphamide, methotrexate, and even rituximab. Use of these agents is not widespread given toxicity risks and lack of staunch prospective clinical trials [85-87]. IL-6 inhibitors are not currently used in refractory cases of KD. A 2017 prospective case series by Nozawa et al. reported progressive development of giant coronary artery aneurysms in 2 out of 4 children treated with tocilizumab with refractory KD. While this was a single small series, there is a suggestion than tocilizumab may accelerate formation of CALs [88].

\section{Primary Prevention of Thrombosis}

Patients with no evidence of CALs are maintained on low-dose ASA therapy throughout the acute phase of illness. At the 68 week follow-up appointment, ASA may be discontinued so long as no adverse changes are seen on the final cardiac imaging (echocardiogram). Patients with small CALs are typically continued on low-dose ASA monotherapy past this period. Those with moderate-sized aneurysms are managed with ASA and an ADP receptor antagonist, i.e., clopidogrel. Children with persistent large or giant aneurysms (internal luminal diameter $\geq 8 \mathrm{~mm}$ ) may be treated with an antiplatelet agent plus anticoagulant therapy (i.e., warfarin or LMWH). The latter regimens are implemented in collaboration with pediatric hematology specialists. It is important to note that nonsteroidal anti-inflammatory drugs, which utilize the cyclooxygenase pathway, may interfere with the antiplatelet effect of ASA and should be avoided. 
Studies are underway assessing the role of 3-hydroxy-3methylglutaryl coenzyme A reductase inhibitors (statins) in children with KD and CALs. Statins may have potential beneficial effects on inflammation, platelet aggregation, coagulation, and endothelial function in addition to their known cholesterol lowering effects. Studies have shown both safety and tolerability, but long-term prospective trials are needed prior to recommending their routine use in $\mathrm{KD}[89,90]$.

\section{Prognosis and Long-Term Management}

The prognosis for children diagnosed with Kawasaki disease is primarily based upon extent and severity of coronary artery involvement at diagnosis and at follow-up. The case-fatality rate in the United States and Japan is less than $0.2 \%$, and the principal cause of death is myocardial infarction resulting from coronary artery occlusion [91]. The AHA 2017 guidelines for diagnosis, treatment, and management of $\mathrm{KD}$ provide a detailed risk classification scheme that can be utilized for follow-up guidance [38•]. The classification system is divided into five risk categories utilizing both $Z$ scores and absolute luminal dimensions.

The lowest risk level is 1, indicating no involvement of the coronary arteries $(Z$ score $<2)$. These patients are screened with echocardiogram during the acute illness, and then again at 6-8 weeks after onset. These patients appear to have a similar risk profile to patients without a diagnosis of $\mathrm{KD}$ [49]. ASA can be discontinued in this group so long as there are no adverse changes in the risk classification. The highest risk group is risk level 5 with large or giant aneurysms ( $Z$ score $\geq 10$ or absolute dimension $\geq 8 \mathrm{~mm}$ ). These patients naturally require much closer cardiac monitoring, and even addition of anticoagulants if persistence of aneurysms as outlined above $\left[38^{\bullet}\right]$.

\section{Compliance with Ethical Standards}

Conflict of Interest The authors declare that they have no conflicts of interest.

Human and Animal Rights and Informed Consent This article does not contain any studies with human or animal subjects performed by any of the authors.

\section{References}

Papers of particular interest, published recently, have been highlighted as:

- Of importance

1. Makino N, Nakamura Y, Yashiro M, Kosami K, et al. The Nationwide epidemiologic survey of Kawasaki disease in Japan, 2015-2016. Pediatr Int. 2019;61(4):397-403. https://doi.org/10. 1111/ped.13809 Provides the most up-to-date epidemiologic survey on Kawasaki Disease in Japan.

2. Makino N, Nakamura Y, Yashiro M, Ae R, Tsuboi S, Aoyama Y, et al. Descriptive epidemiology of Kawasaki disease in Japan, 2011-2012: from the results of the 22nd nationwide survey. J Epidemiol. 2015;25(3):239-45.

3. Maddox RA, Person MK, Lindsay JL, Baherling DL, et al. Abstract 0.03: Monitoring the occurrence of Kawasaki syndrome in the United States. Circulation. Abstracts from the Eleventh International Kawasaki Disease Symposium. 2015;131(suppl 2).

4. Holman RC, Christensen KY, Belay ED, Steiner CA, Effler PV, Miyamura J, et al. Racial/ethnic differences in the incidence of Kawasaki syndrome among children in Hawaii. Hawaii Med J. 2010;69:194-7.

5. Bell DM, Morens DM, Holman RC, Hurwitz ES, Hunter MK. Kawasaki syndrome in the United States: 1976 to 1980 . Am J Dis Child. 1983;137(3):211-4. https://doi.org/10.1001/archpedi.1983. 02140290003001 .

6. Holman RC, Christensen KY, Belay ED, et al. Racial/ethnic differences in the incidence of Kawasaki syndrome among children in Hawaii. Hawaii Med J. 2010;69(8):194-7.

7. Fujita Y, Nakamura Y, Sakata K, Hara N, Kobayashi M, Nagai M, et al. Kawasaki disease in families. Pediatrics. 1989;84:666-9.

8. Kottek A, Shimizu C, Burns JC. Kawasaki disease in monozygotic twins. Pediatr Infect Dis J. 2011;30(12):1114-6. https://doi.org/10. 1097/INF.0b013e31822ac4ff.

9. Harada F, Sada M, Kamiya T, Yanase Y, Kawasaki T, Sasazuki T. Genetic analysis of Kawasaki syndrome. Am J Hum Genet. 1986;39(4):537-9.

10. Uehara R, Yashiro M, Nakamura Y, Yanagawa H. Kawasaki disease in parents and children. Acta Paediatr. 2003;92:694-7. https:// doi.org/10.1111/j.1651-2227.2003.tb00602.x.

11. Dergun M, Kao A, Hauger SB, Newburger JW, Burns JC. Familial occurrence of Kawasaki syndrome in North America. Arch Pediatr Adolesc Med. 2005;159(9):876-81. https://doi.org/10.1001/ archpedi.159.9.876.

12. Uehara R, Yashiro M, Nakamura Y, Yanagawa H. Clinical features of patients with Kawasaki disease whose parents had the same disease. Arch Pediatr Adolesc Med. 2004;158:1166-9.

13. Onouchi Y, Ozaki K, Buns JC, Shimizu C, Hamada H, Honda T, et al. Common variants in CASP3 confer susceptibility to Kawasaki disease. Hum Mol Genet. 2010;19(14):2898-906. https://doi.org/ $10.1093 / \mathrm{hmg} / \mathrm{ddq} 176$

14. Onouchi Y, Ozaki K, Burns JC, et al. A genome-wide association study identifies three new risk loci for Kawasaki disease. Nat Genet. 2012;44(5):517-21. https://doi.org/10.1038/ng.2220.

15. Onouchi Y, Gunji T, Burns JC, Shimizu C, Newburger JW, Yashiro M, et al. ITPKC functional polymorphism associated with Kawasaki disease susceptibility and formation of coronary artery aneurysms. Nat Genet. 2008;40(1):35-42. https://doi.org/10.1038/ ng.2007.59.

16. Onouchi Y. Genetics of Kawasaki disease: what we know and don't know. Circ J. 2012;76(7):1581-6. https://doi.org/10.1253/circj.cj12-0568.

17. Abrams JY, Weintraub ES, Baggs JM, McCarthy NL, Schonberger LB, Lee GM, et al. Childhood vaccines and Kawasaki disease, Vaccine Safety Datalink, 1996-2006. Vaccine. 2015;33(2):382-7. https://doi.org/10.1016/j.vaccine.2014.10.044.

18. Baker MA, Baer B, Kulldorff M, Zichittella L, Reindel R, DeLuccia S, et al. Kawasaki disease and 13-valent pneumococcal conjugate vaccination among young children: a self-controlled risk interval and cohort study with null results. PLoS Med. 2019;16(7): e1002844. https://doi.org/10.1371/journal.pmed.1002844.

19. Hall GC, Tulloh RM, Tulloh LE. The incidence of Kawasaki disease after vaccination within the UK pre-school National Immunisation Programme: an observational THIN database study. 
Pharmacoepidemiol Drug Saf. 2016;25(11):1331-6. https://doi. org/10.1002/pds.4108.

20. L'Huillier AG, Brito F, Wagner N, Cordey S, Zdobnov E, PosfayBarbe KM, et al. Identification of viral signatures using highthroughput sequencing on blood of patients with Kawasaki disease. Front Pediatr. 2019;7:524. https://doi.org/10.3389/fped.2019. 00524.

21. Burns JC, Herzog L, Fabri O, Tremoulet AH, Rodó X, Uehara R, et al. Seasonality of Kawasaki disease: a global perspective. PLoS One. 2013;8(9):e74529. https://doi.org/10.1371/journal.pone. 0074529.

22. Uehara R, Belay ED. Epidemiology of Kawasaki disease in Asia, Europe, and the United States. J Epidemiol. 2012;22(2):79-85. https://doi.org/10.2188/jea.je20110131.

23. Rodó X, Ballester J, Cayan D, Melish ME, Nakamura Y, Uehara R, et al. Association of Kawasaki disease with tropospheric wind patterns. Sci Rep. 2011;1:152. https://doi.org/10.1038/srep00152.

24. Rodó X, Curcoll R, Robinson M, et al. Tropospheric winds from northeastern China carry the etiologic agent of Kawasaki disease from its source to Japan. Proc Natl Acad Sci U S A. 2014;111(22): 7952-7. https://doi.org/10.1073/pnas.1400380111.

25. Jorquera H, Borzutzky A, Hoyos-Bachiloglu R, García A. Association of Kawasaki disease with tropospheric winds in Central Chile: is wind-borne desert dust a risk factor? Environ Int. 2015;78:32-8. https://doi.org/10.1016/j.envint.2015.02.007.

26. Jaggi P, Kajon AE, Mejias A, Ramilo O, Leber A. Human adenovirus infection in Kawasaki disease: a confounding bystander? Clin Infect Dis. 2013;56(1):58-64. https://doi.org/10.1093/cid/cis807.

27. Gedalia A. Kawasaki disease: 40 years after the original report. Curr Rheumatol Rep. 2007;9(4):336-41. https://doi.org/10.1007/ s11926-007-0053-7.

28. Alphonse MP, Duong TT, Shumitzu C, Hoang TL, McCrindle BW, Franco A, et al. Inositol-triphosphate 3-kinase C mediates inflammasome activation and treatment response in Kawasaki disease. J Immunol. 2016;197(9):3481-9. https://doi.org/10.4049/ jimmunol.1600388.

29. Anzai F, Watanabe S, Kimura H, Kamata R, Karasawa T, Komada $\mathrm{T}$, et al. Crucial role of NLRP3 inflammasome in a murine model of Kawasaki disease. J Mol Cell Cardiol. 2020;138:185-96. https:// doi.org/10.1016/j.yjmcc.2019.11.158.

30. Swanson KV, Deng M, Ting JP. The NLRP3 inflammasome: molecular activation and regulation to therapeutics. Nat Rev Immunol. 2019;19(8):477-89. https://doi.org/10.1038/s41577-019-0165-0.

31. Franco A, Shimizu C, Tremoulet AH, Burns JC. Memory T-cells and characterization of peripheral T-cell clones in acute Kawasaki disease. Autoimmunity. 2010;43(4):317-24. https://doi.org/10. 3109/08916930903405891.

32. Rowley AH, Eckerley CA, Jäck HM, Shulman ST, Baker SC. IgA plasma cells in vascular tissue of patients with Kawasaki syndrome. J Immunol. 1997;159(12):5946-55.

33. Rowley AH, Shulman ST, Mask CA, Finn LS, Terai M, Baker SC, et al. IgA plasma cell infiltration of proximal respiratory tract, pancreas, kidney, and coronary artery in acute Kawasaki disease. J Infect Dis. 2000;182(4):1183-91. https://doi.org/10.1086/315832.

34. Lindquist ME, Hicar MD. B cells and antibodies in Kawasaki disease. Int J Mol Sci. 2019;20(8):1834. https://doi.org/10.3390/ ijms20081834.

35. Franco A, Touma R, Song Y, Shimizu C, Tremoulet AH, Kanegaye JT, et al. Specificity of regulatory T cells that modulate vascular inflammation. Autoimmunity. 2014;47(2):95-104. https://doi.org/ 10.3109/08916934.2013.860524.

36. Doi M, Takeda T, Sakurai Y, et al. Altered immunoglobulin A and $M$ levels associated with changes in BAFF and APRIL after administration of intravenous immunoglobulin to treat Kawasaki disease. J Investig Allergol Clin Immunol. 2010;20(5):413-8.
37. Ha KS, Jang G, Lee J, Lee KC, Hong YS, Son CS, et al. Incomplete clinical manifestation as a risk factor for coronary artery abnormalities in Kawasaki disease: a meta-analysis. Eur J Pediatr. 2013;172(3):343-9. https://doi.org/10.1007/s00431-012-1891-5.

38. McCrindle BW, Rowley AH, Newburger JW, et al. Diagnosis, treatment, and long-term management of Kawasaki disease: a scientific statement for health professionals from the American Heart Association [published correction appears in circulation. 2019 Jul 30;140(5):e181-e184]. Circulation. 2017;135(17):e927-e999. https://doi.org/10.1161/CIR.0000000000000484 The most recent evidence-based guidance for healthcare professionals who manage Kawasaki disease. A comprehensive resource.

39. Yanagawa H, Nakamura Y, Yashiro M, Ojima T, Tanihara S, Oki I, et al. Results of the nationwide epidemiologic survey of Kawasaki disease in 1995 and 1996 in Japan. Pediatrics. 1998;102(6):E65. https://doi.org/10.1542/peds.102.6.e65.

40. Maddox RA, Holman RC, Uehara R, Callinan LS, Guest JL, Schonberger LB, et al. Recurrent Kawasaki disease: USA and Japan. Pediatr Int. 2015;57(6):1116-20. https://doi.org/10.1111/ ped.12733.

41. Kil HR, Yu JW, Lee SC, Rhim JW, Lee KY. Changes in clinical and laboratory features of Kawasaki disease noted over time in Daejeon, Korea. Pediatr Rheumatol Online J. 2017;15(1):60. https://doi.org/10.1186/s12969-017-0192-y.

42. Tremoulet AH, Jain S, Chandrasekar D, Sun X, Sato Y, Burns JC. Evolution of laboratory values in patients with Kawasaki disease. Pediatr Infect Dis J. 2011;30(12):1022-6. https://doi.org/10.1097/ INF.0b013e31822d4f56.

43. Eladawy M, Dominguez SR, Anderson MS, Glodé MP. Abnormal liver panel in acute Kawasaki disease. Pediatr Infect Dis J. 2011;30(2):141-4. https://doi.org/10.1097/INF.0b013e3181f6fe2a.

44. Shike H, Kanegaye JT, Best BM, Pancheri J, Burns JC. Pyuria associated with acute Kawasaki disease and fever from other causes. Pediatr Infect Dis J. 2009;28(5):440-3. https://doi.org/10. 1097/INF.0b013e318193ec8e.

45. Kwon H, Lee JH, Jung JY, Kwak YH, Kim DK, Jung JH, et al. Nterminal pro-brain natriuretic peptide can be an adjunctive diagnostic marker of hyper-acute phase of Kawasaki disease. Eur J Pediatr. 2016;175(12):1997-2003. https://doi.org/10.1007/s00431-01627983.

46. Dahdah N, Siles A, Fournier A, Cousineau J, Delvin E, Saint-Cyr $\mathrm{C}$, et al. Natriuretic peptide as an adjunctive diagnostic test in the acute phase of Kawasaki disease. Pediatr Cardiol. 2009;30(6):810 7. https://doi.org/10.1007/s00246-009-9441-2.

47. Lin KH, Chang SS, Yu CW, Lin SC, Liu SC, Chao HY, et al. Usefulness of natriuretic peptide for the diagnosis of Kawasaki disease: a systematic review and meta-analysis. BMJ Open. 2015;5(4):e006703. https://doi.org/10.1136/bmjopen-2014006703.

48. Yi L, Zhang J, Zhong J, Zheng Y. Elevated levels of platelet activating factor and its acetylhydrolase indicate high risk of Kawasaki disease. J Interferon Cytokine Res. 2019;40(3). https://doi.org/10. 1089/jir.2019.0141 A novel new test that may be utilized in the future to help predict Kawasaki disease during the acute phase. More studies need to be conducted prior to its routine use in clinical practice.

49. Kato H, Sugimura T, Akagi T, Sato N, Hashino K, Maeno Y, et al. Long-term consequences of Kawasaki disease. A 10- to 21-year follow-up study of 594 patients. Circulation. 1996;94(6):1379-85. https://doi.org/10.1161/01.cir.94.6.1379.

50. Research Committee on Kawasaki Disease. Report of Subcommittee on Standardization of Diagnostic Criteria and Reporting of Coronary Artery Lesions in Kawasaki Disease. Tokyo: Japanese Ministry of Health and Welfare; 1984.

51. Kavey RE, Allada V, Daniels SR, et al. Cardiovascular risk reduction in high-risk pediatric patients: a scientific statement from the 
American Heart Association Expert Panel on Population and Prevention Science; the Councils on Cardiovascular Disease in the Young, Epidemiology and Prevention, Nutrition, Physical Activity and Metabolism, High Blood Pressure Research, Cardiovascular Nursing, and the Kidney in Heart Disease; and the Interdisciplinary Working Group on Quality of Care and Outcomes Research: endorsed by the American Academy of Pediatrics. Circulation. 2006;114(24):2710-38. https://doi.org/10.1161/ CIRCULATIONAHA.106.179568.

52. Beiser AS, Takahashi M, Baker AL, Sundel RP, Newburger JW. A predictive instrument for coronary artery aneurysms in Kawasaki disease. US Multicenter Kawasaki Disease Study Group. Am J Cardiol. 1998;81(9):1116-20. https://doi.org/10.1016/s00029149(98)00116-7.

53. Royal College of Paediatrics and Child Health Guidance: Paediatric multisystem inflammatory syndrome temporally associated with COVID-19. 2020. A newly described Kawasaki-like disease associated with an infectious trigger. May help further support an infectious agent as the trigger in Kawasaki disease. Further studies are underway.

54. Riphagen S, Gomez X, Gonzales-Martinez C, Wilkinson N, Theocharis P. Hyperinflammatory shock in children during COVID-19 pandemic. Lancet. 2020. Advance online publication, https://doi.org/10.1016/S0140-6736(20)31094 A newly described Kawasaki-like disease associated with an infectious trigger. May help further support an infectious agent as the trigger in Kawasaki disease

55. Verdoni L, Mazza A, Gervasoni A, Martelli L, et al. An outbreak of severe Kawasaki-like disease at the Italian epicentre of the SARSCoV-2 epidemic: an observational cohort study. Lancet. 2020. Advance online publication, https://doi.org/10.1016/S01406736(20)31103-X A newly described Kawasaki-like disease associated with an infectious trigger. Largest cohort to date. May help further support an infectious agent as the trigger in Kawasaki disease.

56. Belhadjer Z, Méot M, Bajolle F, et al. Acute heart failure in multisystem inflammatory syndrome in children (MIS-C) in the context of global SARS-CoV-2 pandemic. Circulation. 2020;382:1370-22. https://doi.org/10.1161/CIRCULATIONAHA.120.048360 All of the articles (53-58) are important as they are the first data we are seeing on this new entity. Hopefully, with new international surveillance and data, we may gain better insight into KD as well given the significant overlap features with MIS-C.

57. Toubiana J, Poirault C, Corsia A, et al. Outbreak of Kawasaki disease in children during COVID-19 pandemic: a prospective observational study in Paris, France. medRxiv. Preprint posted. 2020. https://doi.org/10.1101/2020.05.10.20097394 Emerging data on this new entitiy from France.

58. Centers for Disease Control and Prevention Health Alert Network (HAN). Multisystem inflammatory syndrome in children (MIS-C) associated with Coronavirus Disease 2019 (COVID-19). Available at: https://emergency.cdc.gov/han/2020/han00432.asp. Accessed on June 12,2020 The first clinical criteria formulated for this new Kawasaki-like entity.

59. Wu MH, Chen HC, Yeh SJ, et al. Prevalence and the long-term coronary risks of patients with Kawasaki disease in a general population $<40$ years: a national database study. Circ Cardiovasc Qual Outcomes. 2012;5:566-70.

60. Newburger JW, Takahashi M, Burns JC, Beiser AS, Chung KJ, Duffy CE, et al. The treatment of Kawasaki syndrome with intravenous gamma globulin. N Engl J Med. 1986;315(6):341-7. https://doi.org/10.1056/NEJM198608073150601.

61. Newburger JW, Takahashi M, Gerber MA, Gewitz MH, Tani LY, Burns JC, et al. Diagnosis, treatment, and long-term management of Kawasaki disease: a statement for health professionals from the committee on rheumatic fever, endocarditis, and Kawasaki disease, council on cardiovascular disease in the Young, American Heart Association [published correction appears in Pediatrics. 2005 Apr;115(4):1118. Pediatrics. 2004;114(6):1708-33. https://doi. org/10.1542/peds.2004-2182.

62. Mori M, Miyamae T, Imagawa T, Katakura S, Kimura K, Yokota S. Meta-analysis of the results of intravenous gamma globulin treatment of coronary artery lesions in Kawasaki disease. Mod Rheumatol. 2004;14(5):361-6. https://doi.org/10.1007/s10165004-0324-3.

63. Ashouri N, Takahashi M, Dorey F, Mason W. Risk factors for nonresponse to therapy in Kawasaki disease. J Pediatr. 2008;153(3):365-8. https://doi.org/10.1016/j.jpeds.2008.03.014.

64. Li X, Chen Y, Tang Y, et al. Predictors of intravenous immunoglobulin-resistant Kawasaki disease in children: a metaanalysis of 4442 cases. Eur J Pediatr. 2018;177(8):1279-92. https://doi.org/10.1007/s00431-018-3182-2 This article helps us to better stratify patients with Kawasaki disease based on risk. This is important as higher risk patients may benefit from more aggressive therapy in addition to standard therapy during the acute phase of disease.

65. Zheng X, Yue P, Liu L, et al. Efficacy between low and high dose aspirin for the initial treatment of Kawasaki disease: current evidence based on a meta-analysis. PLoS One. 2019;14(5):e0217274. https://doi.org/10.1371/journal.pone.0217274 This study has implications for possibly changing the dose of ASA in primary treatment of Kawasaki disease in the future.

66. Baumer JH, Love SJ, Gupta A, Haines LC, Maconochie I, Dua JS. Salicylate for the treatment of Kawasaki disease in children. Cochrane Database Syst Rev. 2006;4:CD004175. https://doi.org/ 10.1002/14651858.CD004175.pub2.

67. Chen S, Dong Y, Kiuchi MG, Wang J, Li R, Ling Z, et al. Coronary artery complication in Kawasaki disease and the importance of early intervention: a systematic review and meta-analysis. JAMA Pediatr. 2016;170:1156-63.

68. Wardle AJ, Connolly GM, Seager MJ, Tulloh RM. Corticosteroids for the treatment of Kawasaki disease in children. Cochrane Database Syst Rev. 2017;1:CD011188 The most recent randomized control trial assessing the impact of corticosteroid use in the treatment of children with Kawasaki disease.

69. Newburger JW, Sleeper LA, McCrindle BW, Minich LL, Gersony W, Vetter VL, et al. Pediatric heart network investigators. Randomized trial of pulsed corticosteroid therapy for primary treatment of Kawasaki disease. N Engl J Med. 2007;356(7):663-75. https://doi.org/10.1056/NEJMoa061235.

70. Sundel RP, Baker AL, Fulton DR, Newburger JW. Corticosteroids in the initial treatment of Kawasaki disease: report of a randomized trial. J Pediatr. 2003;142:611-6.

71. Inoue $\mathrm{Y}$, Okada $\mathrm{Y}$, Shinohara M, Kobayashi T, Kobayashi T, Tomomasa $\mathrm{T}$, et al. A multicenter prospective randomized trial of corticosteroids in primary therapy for Kawasaki disease: clinical course and coronary artery outcome. J Pediatr. 2006;149:336-41.

72. Kobayashi T, Saji T, Otani T, Takeuchi K, Nakamura T, Arakawa $\mathrm{H}$, et al. Efficacy of immunoglobulin plus prednisolone for prevention of coronary artery abnormalities in severe Kawasaki disease (RAISE study): a randomised, open-label, blinded-endpoints trial. Lancet. 2012;379:1613-20.

73. Chen S, Dong Y, Yin Y, Krucoff MW. Intravenous immunoglobulin plus corticosteroid to prevent coronary artery abnormalities in Kawasaki disease: a meta-analysis. Heart. 2013;99(2):76-82. https://doi.org/10.1136/heartjnl-2012-302126.

74. Kimura M, Harazaki M, Fukuoka T, Asakura I, Sakai H, Kamimaki $\mathrm{T}$, et al. Targeted use of prednisolone with the second IVIG dose for refractory Kawasaki disease. Pediatr Int. 2017;59:397-403.

75. Leung DY, Geha RS, Newburger JW, Burns JC, Fiers W, Lapierre LA, et al. Two monokines, interleukin 1 and tumor necrosis factor, render cultured vascular endothelial cells susceptible to lysis by 
antibodies circulating during Kawasaki syndrome. J Exp Med. 1986;164(6):1958-72. https://doi.org/10.1084/jem.164.6.1958.

76. Tremoulet AH, Jain S, Jaggi P, Jimenez-Fernandez S, Pancheri JM, Sun $\mathrm{X}$, et al. Infliximab for intensification of primary therapy for Kawasaki disease: a phase 3 randomised, double-blind, placebocontrolled trial. Lancet. 2014;383(9930):1731-8. https://doi.org/ 10.1016/S0140-6736(13)62298-9.

77. Son MB, Gauvreau K, Burns JC, et al. Infliximab for intravenous immunoglobulin resistance in Kawasaki disease: a retrospective study. J Pediatr. 2011;158(4):644-649.e1. https://doi.org/10.1016/ j.jpeds.2010.10.012.

78. Portman MA, Dahdah NS, Slee A, et al. Etanercept with IVIG for acute Kawasaki disease: a randomized controlled trial. Pediatrics. 2019;143(6):e20183675. https://doi.org/10.1542/peds.2018-3675 The most recent randomized control trial utilizing tumor necrosis factor inhibitors in the acute phase of Kawasaki disease.

79. Cohen S, Tacke CE, Straver B, Meijer N, Kuipers IM, Kuijpers TW. A child with severe relapsing Kawasaki disease rescued by IL-1 receptor blockade and extracorporeal membrane oxygenation. Ann Rheum Dis. 2012;71(12):2059-61. https://doi.org/10.1136/ annrheumdis-2012-201658.

80. Shafferman A, Birmingham JD, Cron RQ. High dose Anakinra for treatment of severe neonatal Kawasaki disease: a case report. Pediatr Rheumatol Online J. 2014;12:26. https://doi.org/10.1186/ 1546-0096-12-26.

81. Kone-Paut I, Cimaz R, Herberg J, Bates O, Carbasse A, Saulnier JP, et al. The use of interleukin 1 receptor antagonist (anakinra) in Kawasaki disease: a retrospective cases series. Autoimmun Rev. 2018;17(8):768-74. https://doi.org/10.1016/j.autrev.2018.01.024.

82. Hamada H, Suzuki H, Onouchi Y, et al. Efficacy of primary treatment with immunoglobulin plus ciclosporin for prevention of coronary artery abnormalities in patients with Kawasaki disease predicted to be at increased risk of non-response to intravenous immunoglobulin (KAICA): a randomised controlled, open-label, blinded-endpoints, phase 3 trial [published correction appears in Lancet. 2019 Mar 30;393(10178):1298] [published correction appears in Lancet. 2019 Apr 13;393(10180):1504]. Lancet. 2019;393(10176):1128-1137. https://doi.org/10.1016/S01406736(18)32003-8 A promising study that adds a potential beneficial adjunctive primary therapy option in high-risk patients with Kawasaki disease. This study also demonstrated a good safety profile for Cyclosporine use.

83. Okada S, Azuma Y, Suzuki Y, Yamada H, Wakabayashi-Takahara M, Korenaga Y, et al. Adjunct cyclosporine therapy for refractory Kawasaki disease in a very young infant. Pediatr Int. 2016;58(4): 295-8. https://doi.org/10.1111/ped.12778.

84. Tremoulet AH, Pancoast P, Franco A, et al. Calcineurin inhibitor treatment of intravenous immunoglobulin-resistant Kawasaki disease. J Pediatr. 2012;161(3):506-512.e1. https://doi.org/10.1016/j. jpeds.2012.02.048.

85. Hokosaki T, Mori M, Nishizawa T, Nakamura T, Imagawa T, Iwamoto $\mathrm{M}$, et al. Long-term efficacy of plasma exchange treatment for refractory Kawasaki disease. Pediatr Int. 2012;54(1):99 103. https://doi.org/10.1111/j.1442-200X.2011.03487.x.

86. Sauvaget E, Bonello B, David M, Chabrol B, Dubus JC, Bosdure E. Resistant Kawasaki disease treated with anti-CD20. J Pediatr. 2012;160(5):875-6. https://doi.org/10.1016/j.jpeds.2012.01.018.

87. Lee TJ, Kim KH, Chun JK, Kim DS. Low-dose methotrexate therapy for intravenous immunoglobulin-resistant Kawasaki disease. Yonsei Med J. 2008;49(5):714-8. https://doi.org/10.3349/ymj. 2008.49.5.714.

88. Nozawa T, Imagawa T, Ito S. Coronary-artery aneurysm in tocilizumab-treated children with Kawasaki disease. N Engl J Med. 2017;377(19):1894-6. https://doi.org/10.1056/ NEJMc1709609.

89. Tremoulet AH, Jain S, Jone PN, et al. Phase I/IIa trial of atorvastatin in patients with acute Kawasaki disease with coronary Aartery aneurysm. J Pediatr. 2019;215:107-117.e12. https://doi.org/10.1016/ j.jpeds.2019.07.064.

90. Huang SM, Weng KP, Chang JS, Lee WY, Huang SH, Hsieh KS. Effects of statin therapy in children complicated with coronary arterial abnormality late after Kawasaki disease: a pilot study. Circ J. 2008;72(10):1583-7. https://doi.org/10.1253/circj.cj-08-0121.

91. Hayasaka S, Nakamura Y, Yashiro M, Uehara R, Oki I, Tajimi M, et al. Analysis of fatal cases of Kawasaki disease in Japan using vital statistical data over 27 years. J Epidemiol. 2003;13:246-50.

Publisher's Note Springer Nature remains neutral with regard to jurisdictional claims in published maps and institutional affiliations. 